\title{
Primary leiomyoma of the left ventricle leading to sudden and unexpected death in a 74-year-old male: a case report
}

\author{
James J. Yahaya ${ }^{1,2}$ (D)
}

\begin{abstract}
Background: Primary cardiac tumours arising from smooth muscle cells are said to be very rare in the literature. Primary leiomyoma of the heart particularly in men is extremely rare. To the best of my knowledge, there are only two reported cases of boys with primary leiomyoma of the heart in the English literature. Most of leiomyoma tumours involving the heart reported in the literature are a result of cardiac extensions of intravenous leiomyomatosis through the inferior vena cava.

Case presentation: A case of left ventricular primary leiomyoma in a 74-year-old male is reported. He had no known previous history of heart disease but he died suddenly and unexpectedly. At autopsy, the heart measured $420 \mathrm{gm}$ and when it was opened, a solid tumour of size $4 \times 3 \times 2 \mathrm{~cm}$ involving the lower left ventricle on the anterior aspect of the heart was found. The tumour was extending to the left ventricular septum and was growing by protruding into the left ventricle chamber which finally was confirmed histopathologically to be a leiomyoma.

Conclusion: Cardiac benign tumours are rare and can be life threatening because of embolization following their detachment which is manifested clinically by stroke. Additionally, they are clinically asymptomatic; therefore, they cannot be easily detected. In case of clinical suspicion, echocardiography and other imaging diagnostic tests should be used to confirm presence of a tumour.
\end{abstract}

Keywords: Cardiac tumours, Leiomyoma, Sudden death

\section{Background}

Primary leiomyomas of the heart are extremely rare. Those which occur are a result of cardiac extensions of intravenous leiomyomatosis through the inferior vena cava (Melo et al. 2012). Others result from metastatic benign leiomyoma (MBL) and also from venous seeding following hysterectomy in case of women patients (Consamus et al. 2014). Autopsy reports have reported a very low incidence of primary leiomyoma of the heart which ranges from 0.001 to $0.03 \%$ among which $75 \%$ are benign and 25\% are malignant (Song et al. 2014). Mylones

Correspondence: mashimba2009@yahoo.com

${ }^{1}$ Department of Pathology, Makerere College of Health Sciences (MakCHS), Makerere University, P. O. Box 7072, Kampala, Uganda

${ }^{2}$ Department of Biomedical Science, College of Health Sciences (CHS), The University of Dodoma, Dodoma, Tanzania (c) The Author(s). 2020 Open Access This article is licensed under a Creative Commons Attribution 4.0 International License, which permits use, sharing, adaptation, distribution and reproduction in any medium or format, as long as you give appropriate credit to the original author(s) and the source, provide a link to the Creative Commons licence, and indicate if changes were made. The images or other third party material in this article are included in the article's Creative Commons licence, unless indicated otherwise in a credit line to the material. If material is not included in the article's Creative Commons licence and your intended use is not permitted by statutory regulation or exceeds the permitted use, you will need to obtain permission directly from the copyright holder. To view a copy of this licence, visit http://creativecommons.org/licenses/by/4.0/. 
Other benign cardiac tumours include lipoma, papillary fibroelastoma, rhabdomyoma lymphangioma, hemangioma, neurofibroma and ganglioma among many others (Parker et al. 2018). Primary malignant tumours of the heart are less common compared to benign ones and secondary cardiac tumours occur more frequently than primary malignant tumours (Meddeb et al. 2018). Angiosarcoma is the most common primary malignant cardiac tumour accounting for $30 \%$ followed by rhabdomyosarcoma which has a prevalence of $20 \%$ (Li et al. 2016).

Herein, the case of a 74-year-old male who died suddenly due to primary leiomyoma involving the lower left anterior ventricle extending to involve the interventricular wall is presented. Literature review on detection methods of cardiac tumours together with mechanisms of death in cases with cardiac tumours is also presented.

\section{Case presentation}

A 74-year-old male whose previous history was uneventful died suddenly and unexpectedly. The body was taken for clinical autopsy. The height of the deceased was 162 $\mathrm{cm}$ with signs of dehydration which was marked by sunken eyes without cyanosis or jaundice. Externally, there were no signs of chronic illness or injury. There was no collection of any fluid in the thoracic cavity. The lungs were congested, each weighing $320 \mathrm{gm}$ and 480 gm for the left and right, respectively. Their cut surfaces were oozing watery fluid consistent with left heart failure. The heart was enlarged and weighed $420 \mathrm{gm}$ with a globular shape. All heart chambers and the muscle walls were within normal dimension and all coronary arteries were patent. A tumour involving the lower left ventricle anteriorly extending to the left ventricular septum was growing by protruding into the left ventricle (Fig. 1).

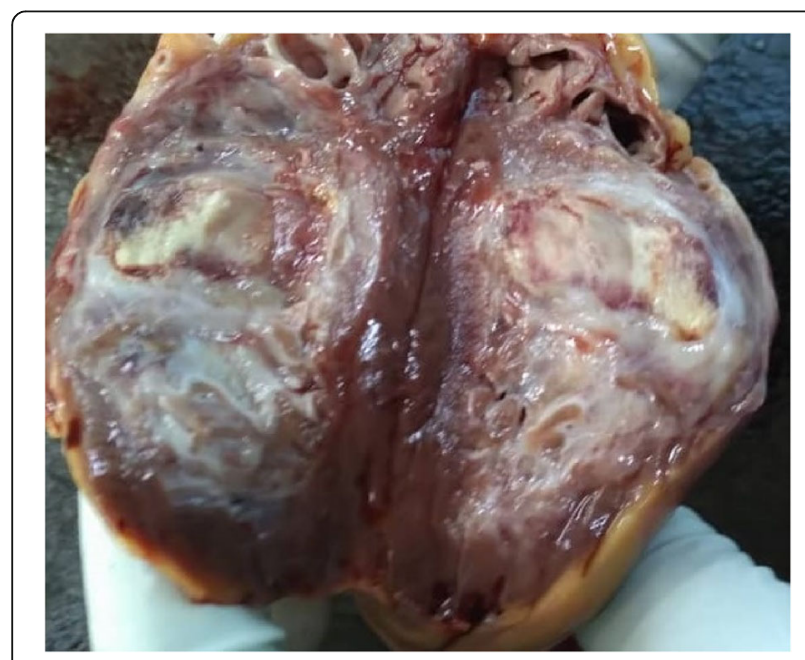

Fig. 1 Gross photograph of the tumour. The tumour is white-tan, well circumscribed
The tumour measured $4 \times 3 \times 2 \mathrm{~cm}$. Macroscopically, the tumour was firm in consistency, white-tan with cotton wool appearance on cut surface. There was no ascitic fluid collection in the abdominal cavity. The prostate gland was enlarged, nodular with size of $80 \mathrm{gm}$ and all other organs were normal.

Microscopically, the tumour was composed of interlacing bundles of bland spindle cells without nuclear atypia or necrosis (Fig. 2). No mitoses were seen. Immunohistochemical stainings included SMA, desmin, S100 and CD117. Both SMA (Fig. 3a) and desmin (Fig. $3 \mathrm{~b})$ were strongly and diffusely positive whereas CD117 and S100 were negative. Therefore, the histological and immunohistochemical findings confirmed the diagnosis of primary leiomyoma of the heart. It was then confirmed that, the cause of sudden and unexpected death was primary leiomyoma of the heart involving the lower left ventricle anteriorly extending to the left ventricular septum. The possible mechanism of death in the present case is that, given the lesion in this case is partly septal, and therefore close to the main branches of the bundle of his, therefore, the cause of death is more likely to be due to arrhythmia.

\section{Discussion}

Patients with primary intracardial leiomyomas (PICLs) are usually asymptomatic. Gaur et al. reviewed four previous asymptomatic cases of PICL in the literature, and added a symptomatic case of their own: the cases ranged

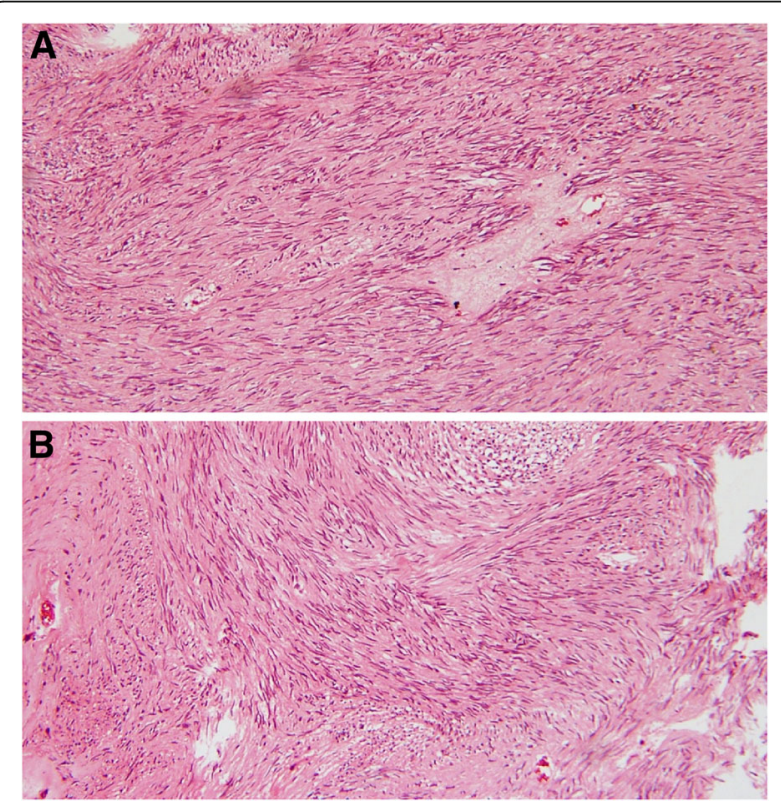

Fig. $\mathbf{2}$ a, $\mathbf{b}$ Both show interlacing bundles of spindle cells without atypia. The tumour cells have uniform nuclei which are slender with tapered ends. No mitosis is seen in the tumour sections $(\mathrm{H}$ and $\mathrm{E}$ stain, $\times 100)$ 


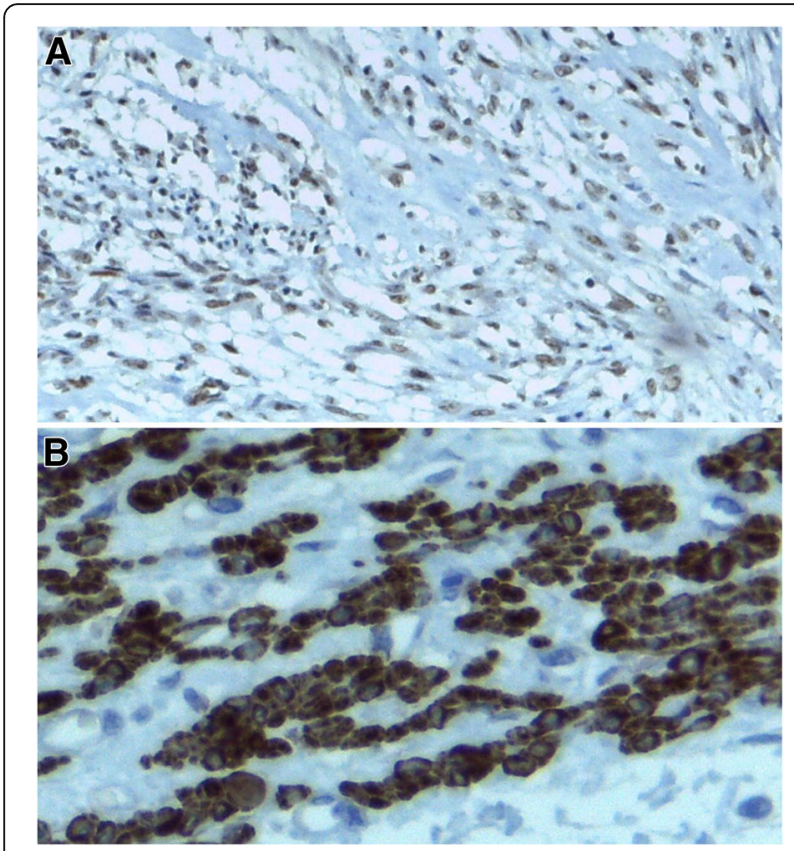

Fig. 3 a Strongly and diffusely intranuclear staining of the tumour cells with SMA $(\mathrm{IHC}, \times 40)$. b Strongly and diffusely intranuclear staining of the tumour cells with desmin $(\mathrm{HC}, \times 100)$

in age from 7 months to 47 years (Gaur et al. 2017). The case described in this report was also asymptomatic and being aged 74 years, it indicates that this is the oldest case with PICL to be reported in the literature and is probably the 6th case of PICL to be documented in the English literature.

The clinical features for PICLs are usually determined by location of the tumour, size and extent of infiltration into the neighbouring tissue. According to the studies done by Meddeb et al., Gaur et al. and Hoffmeier et al. it was reported that, detection of cardiac tumours in life begins by taking history of the patient followed by exclusion of presence of a thrombus or a vegetation. Then echocardiography is the first diagnostic test to be done then if the tumour is not detected, computerised tomography $(\mathrm{CT})$ scan and magnetic resonance imaging (MRI) are used in the process of diagnosis. Additionally, for patients with a risk of coronary stenosis, coronary angiography is done to detect the stenosis (Gaur et al. 2017; Hoffmeier et al. 2014; Meddeb et al. 2018). The advances in diagnosis have helped in increasing the number of cases that can be diagnosed clinically and treated successfully. Patients commonly present clinically with one or more of the three main features of embolism, intracardiac obstruction together with other constitutional symptoms (Consamus et al. 2014). In some cases, the first manifestation of a cardiac tumour is sudden and unexpected death as it was in the case reported in this paper.
The commonest cardiac leiomyomas reported in the literature have been reported in females in whom there was a history of hysterectomy. Metastatic leiomyomas from the uterus which are confirmed by means of immunohistochemical tests involving oestrogen receptor (ER) and progesterone receptor (PR) antibodies are often associated with hemorrhagic pericardial effusion (Just and Schubel 2002). Cardiac tumours cause effects to the heart even death through three mechanisms namely cardiac arrhythmia, obstruction and embolism. For cases in whom the tumour grows by infiltrating into the wall of the heart, the symptoms produced due to the effects of the tumour may include hypertrophy and/or cardiomyopathy of restrictive type and both are dominated clinically by heart failure as it was in the case reported by Centofanti et al. (Centofanti et al. 1999). This is different from the cases in whom cardiac failure is likely to arise as the consequence of the sudden onset of arrhythmia resulting from nerve conduction system of the heart similar to the case reported in this paper.

Studies have shown that fibromas tend to involve the neural pathways of the heart particularly atrioventricular (AV) block and/or the myocardium and cause arrhythmic changes (Hoppe et al. 1997). Embolism of the peripheral vasculature, or a pulmonary artery embolism, which may result from a detached tumour tissue as commonly seen with myxoma due to its gelatinous structure rendering it prone to detachment and/or organization of thrombotic deposits of which can lead to stroke (Qin et al. 2010). For the sake of establishing the source of the embolus, all fragments of embolic material retrieved during diagnostic investigations and at autopsy should be submitted for histological evaluation (Hoffmeier et al. 2014; Hoppe et al. 1997).

Diagnosis of cardiac tumours including primary leiomyomas has dramatically improved as a result of rapid advances that have been made in cardiovascular imaging which can enable the type of cardiac tumours to be accurately predicted. That means patients can choose the proper treatment in time. The progress of diagnosis may account for the high incidence on the whole, also the high ratio of benign tumours. Echocardiography, MRI, CT scan and transesophageal echocardiography have been found useful in determining tumour size and location (Meddeb et al. 2018). When there is suspicion of a malignant tumour to the heart, a CT scan or MRI can improve the diagnostic approach.

\section{Conclusion}

Primary cardiac leiomyomas in males are extremely rare. They can lead to heart failure and therefore, patients with such tumours may present with clinical features of heart failure such as dyspnea, tachycardia, oedema of the lower limbs and fatigue among many others. When such 
symptoms are observed, cardiac imaging diagnostic tests ought to be used for quick detection of the tumours so as to prevent fatal outcomes and even death.

\section{Abbreviations}

$\mathrm{CT}$ : Computed tomography; MRI: Magnetic resonance imaging;

AV: Atrioventricular; ER: Oestrogen receptor; PR: Progesterone receptor; MBL: Metastatic benign leiomyoma

\section{Acknowledgements}

The author would like to thank the morticians at Kampala City Council Authority (KCCA) mortuary for their support.

\section{Author's contributions}

The single author is solely responsible to the design and implementation of the research, to the analysis of the results and to the writing of the manuscript. The author(s) read and approved the final manuscript.

\section{Funding}

This research did not receive any specific grant from funding agencies in the public, commercial or not-for-profit sectors.

\section{Availability of data and materials}

Not applicable

\section{Ethics approval and consent to participate}

Ethical approval was obtained from the institution review board of the school of biomedical science of Makerere College of Health Science (MakCHS) and a reference number SOB/IRB/CR-028/20.

\section{Consent for publication}

Written informed consent was obtained from the next of kin of the deceased and copy of it has been for review by the Editor-in-Chief of the journal when it is needed.

\section{Competing interests}

The author declares that have no competing interests.

Received: 17 March 2020 Accepted: 27 September 2020

Published online: 02 October 2020

\section{References}

Centofanti P, Di Rosa E, Deorsola L, Dato GMA, Patane F, La Torre M et al (1999) Primary cardiac tumors: early and late results of surgical treatment in 91 patients. Ann Thorac Surg 68(4):1236-1241

Consamus EN, Reardon MJ, Ayala AG, Schwartz MR, Ro JY (2014) Case report: metastasizing leiomyoma to heart. Methodist DeBakey Cardiovasc J 10(4):251

Gaur K, Majumdar K, Kisku N, Gondal R, Sakhuja P, Satsangi DK (2017) Primary intracardiac leiomyoma arising from cardiomyocyte progenitors at the right ventriculoseptal interface: case report with literature review. Cardiovasc Pathol 28:46-50

Hoffmeier A, Sindermann JR, Scheld HH, Martens S (2014) Cardiac tumors-diagnosis and surgical treatment. Dtsch Arztebl Int 111(12):205

Hoppe U, La KR, Beuckelmann D, Erdmann E (1997) Heart tumors--their manifestation through uncharacteristic symptoms. Dtsch Med Wochenschr 122(17):551-557

Just S, Schubel B (2002) Tumoren des Herzens: und 12 Tabellen: Verlag HJB.

Li H, Xu D, Zhu N, Dong L, Wang C (2016) Multiple primary leiomyomas in the right ventricle: a rare form of leiomyoma. Ann Thorac Surg 101(2):e33-e35

Meddeb M, Chow RD, Whipps R, Haque R (2018) The heart as a site of metastasis of benign metastasizing leiomyoma: case report and review of the literature. Case Rep Cardiol 2018

Melo IS, Belo F, Gouveia R, Anjos R (2012) Primary cardiac leiomyoma of the ventricular septum: a rare form of pediatric intracardiac tumor. Pediatr Cardiol 33(4):649-651

Mylonas KS, Ziogas IA, Avgerinos DV (2020) Microenvironment in cardiac tumor development: what lies beyond the event horizon? In: Tumor Microenvironments in Organs. Springer, pp 51-56

Parker NA, Dakhil CS, Dakhil SR, Lalich D (2018) Metastasis of benign leiomyomas outside the uterus. Kansas J Med 11(2):56
Qin C, Chen L, Yb X, Bc C (2010) Giant primary leiomyoma of the right ventricle. J Card Surg 25(2):169-171

Song L, Wang L, Huang W-C, Zhou X-M, Hu J-G, Liu L-M (2014) Primary leiomyoma: a rare space occupying lesion in the right ventricle. Ann Thorac Surg 97(1):324-326

\section{Publisher's Note}

Springer Nature remains neutral with regard to jurisdictional claims in published maps and institutional affiliations.

\section{Submit your manuscript to a SpringerOpen ${ }^{\circ}$ journal and benefit from:}

- Convenient online submission

- Rigorous peer review

- Open access: articles freely available online

- High visibility within the field

- Retaining the copyright to your article

Submit your next manuscript at $\boldsymbol{\nabla}$ springeropen.com 